\title{
Tetracycline and Glutathione Inhibit Matrix Metalloproteinase Activity: An In Vitro Study Using Culture Supernatants of L929 and Dalton Lymphoma Cell Lines
}

\author{
Gajanan Kendre, Rahul Raghavan, Sanith Cheriyamundath, and Joseph Madassery \\ Department of Biotechnology, University of Calicut, Malappuram District, Kerala 673635, India \\ Correspondence should be addressed to Joseph Madassery; mjrrd@hotmail.com
}

Received 8 November 2013; Revised 12 December 2013; Accepted 13 December 2013

Academic Editor: Andrea Vecchione

Copyright (c) 2013 Gajanan Kendre et al. This is an open access article distributed under the Creative Commons Attribution License, which permits unrestricted use, distribution, and reproduction in any medium, provided the original work is properly cited.

\begin{abstract}
Tetracycline and glutathione inhibited the protease activities of matrix metalloproteinase- 2 and matrix metalloproteinase- 9 expressed by mouse fibrosarcoma cells (L929) and Dalton lymphoma cells, respectively. The inhibitory activity of the tetracycline may be due to its ability to chelate metal ions such as calcium and zinc. Gelatin-zymography technique was used to demonstrate the inhibitory activity of both tetracycline and glutathione. The intensity of the bands corresponding to metalloproteinase activity in zymography gel was reduced in the presence of $50-100 \mu \mathrm{g} / \mathrm{mL}$ of tetracycline. The presence of $10-100 \mu \mathrm{g} / \mathrm{mL}$ of tetracycline in the medium increased the adherence of L929 cancer cells. These results clearly indicate the antimetastatic property of tetracycline. Reduced glutathione, a compound which is produced endogenously by the cells to maintain the redox status, was shown to inhibit the matrix metalloproteinase activity (in vitro). Therefore, it is assumed that decreased glutathione levels in synovial fluids or plasma might increase the activity of MMP. Reduced glutathione at $100 \mu \mathrm{g} / \mathrm{mL}$ inhibited the metalloproteinase activity in gelatinzymographic gel. As both tetracycline and glutathione exhibited an inhibitory effect on matrix metalloproteinase activity, it was of great interest to check their clinical effects on various MMP associated pathological conditions such as cancer metastasis and arthritis. Here we report that tetracycline and reduced glutathione inhibited the activity of MMP2 completely and activity of MMP9 partly.
\end{abstract}

\section{Introduction}

Matrix metalloproteinases are zinc dependent neutral endopeptidases and they were originally described as collagenolytic factor that is required for the dissolution of tadpole tail [1]. The primary function of MMP is to remodel the extracellular matrix. MMPs are involved in fetal tissue development, tissue repair, and wound healing [2]. MMPs are secreted into the extracellular matrix as zymogen called proMMP and cleavage of propeptide from the proMMP makes it catalytically active [3].

MMP2 and MMP9 are the two gelatinases that can degrade the collagenase IV basement membrane and the overproduction of MMP2 and MMP9 during pathological conditions like cancers is responsible for the cancer cell penetration through extracellular matrix. MMP2 and MMP9 have been associated with the progression of various cancers like breast cancer, colorectal cancer, nonsmall cell lung cancer, and gastric and pancreatic cancer [2].
Previous reports from clinical and knockout mice studies shows that higher expression of metalloproteinase are responsible for severe arthritis $[4,5]$. A congenital disease, Winchester syndrome, is associated with mutation in different matrix metalloproteinase genes and symptoms of this disease were similar to rheumatoid arthritis [6]. Based on these reports, the role of metalloproteinase in development of severe arthritic condition is undoubtfully established.

Doxycycline, an analog of tetracycline, is widely used in the treatment of dental periodontitis. Doxycycline is reported to inhibit MMPs directly [7]. Tetracyclines are bacteriostatic antibiotics which specifically target 30 s ribosome and inhibit the binding of aminoacyl tRNA to the ribosomal A site [8].

In the present study, the tetracycline hydrochloride (achromycin), a well-known antibiotic in clinical use, was found to inhibit the matrix metalloproteinase activity. Although doxycycline is reported to inhibit MMP, no reports are available on the direct inhibition of achromycin on various MMPs. Treatment of L929 mouse fibrosarcoma cells 
with tetracycline could alter the adhesive and migratory properties. GSH was shown to inhibit the matrix metalloproteinase activity indicating that endogenous GSH might also have a role in keeping the metalloproteinase inactive.

\section{Materials and Methods}

2.1. Cell Lines Maintenance and Collection of Supernatant Containing Metalloproteinases. L929 cell line (mouse fibrosarcoma cancer cells) was a kind gift from Central Drug Research Institute, Lucknow, and Dalton lymphoma cell line was obtained from Amala Cancer Hospital and Research Centre, Thrissur, Kerala. L929 and Dalton lymphoma cell lines were maintained in DMEM media with $10 \%$ FBS and antibiotics for 48 hours at $37^{\circ} \mathrm{C}$ in $5 \%$ carbon dioxide environment. Cells were centrifuged at $1200 \mathrm{rpm}$ for 10 minutes and the culture supernatant was collected. The samples were stored at -20 degree Celsius until used for the analysis of metalloproteinase activity.

2.2. Gelatin-Zymography. Gelatin-zymography was performed according to the standard protocol with the following modifications [9]. To determine the metalloproteinase activity in the culture supernatants of L929 and DLA cancer cell lines, SDS-polyacrylamide gel ( $8 \%$ ) with $0.1 \%$ gelatin was prepared and cell culture supernatants were loaded into each well. Electrophoresis was carried out at $100 \mathrm{~V}$ for 2 hours. After electrophoresis, gels were incubated in renaturing buffer (2.5\% triton X) for 30 minutes to remove the SDS. The gels were then washed with developing buffer (Tris base$0.01 \mathrm{M}$, Tris $\mathrm{HCl}-0.03 \mathrm{M}, \mathrm{NaCl}-0.2 \mathrm{M}, \mathrm{CaCl}_{2}-6.6 \mathrm{mM}$, and Tween $20-0.02 \%$ ) and incubated overnight in fresh developing buffer. The gels were stained with coomassie blue R-250 $0.5 \%(\mathrm{w} / \mathrm{v})$ for 30 minutes and destained with coomassive R-250 destaining solution methanol:acetic acid : water $(50: 10: 40)$.

The physical inhibition of MMP by tetracycline and GSH was demonstrated by the following method. The gel lanes with equal quantity of MMP (culture supernatant) were cut into sections and each lane was incubated with varied concentration of inhibitors in developing buffer. The gel lanes incubated in EDTA $(15 \mathrm{mM})$ were taken as positive control for MMP inhibition [10]. After incubation and staining, each gel lane was imaged with HP scanner and densitometric analysis was performed using Image J software [11].

2.3. Cell Adhesion Assay. For cell adhesion assay, $35 \mathrm{~mm}$ culture dishes were first precoated with $0.1 \%$ gelatin and incubated overnight at 4 degree Celsius. The culture dishes were washed with sterile phosphate buffered saline (PBS). $10^{4}$ cells (L929) were seeded into each culture dish along with varied concentrations of tetracycline and incubated for 4 hours in $5 \%$ carbon dioxide atmosphere at $37^{\circ} \mathrm{C}$. The culture supernatant was removed and culture dishes were washed with PBS to remove nonadherent cells. The adherent cells were counted using Image J software [11]. Ten different fields from each culture dish were counted using $10 \mathrm{x}$ objectives

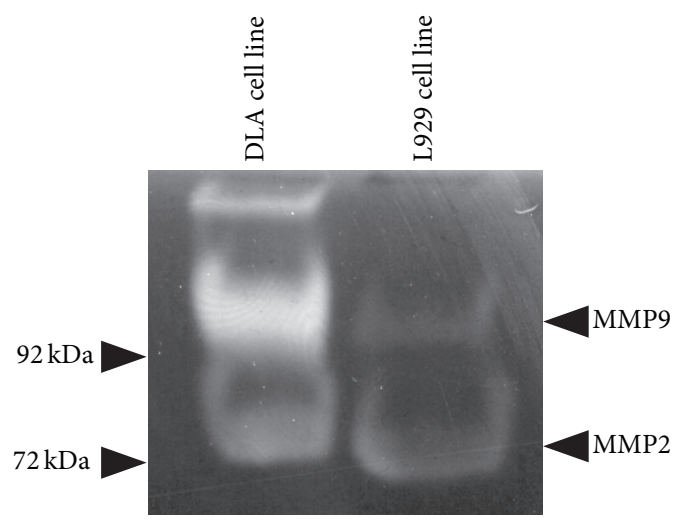

FIGURE 1: Gelatin-zymography gel shows MMP9 and MMP2 in the culture supernatant of DLA cell line and L929 cell line.

and total cell adherence was represented in percentage with respect to control.

2.4. In Vitro Scratch Assay. Cells were plated on $35 \mathrm{~mm}$ culture dishes to create a confluent monolayer. The monolayer is scraped in a straight line using micropipette tip [12]. Debris was removed by washing the plate with DMEM media. The cell culture dishes were then incubated with $50 \mu \mathrm{g} / \mathrm{mL}$ of tetracycline for 24 hours and images of the field were taken before and after the treatment. The number of cells migrated during tetracycline treatment was counted using the Image J software and it was represented in percentage with respect to control [11].

\section{Results}

3.1. Gelatinase Profiling of DLA and L929 Cell Lines. Gelatinzymography revealed the presence of both MMP2 and MMP9 in the culture supernatants of DLA and L929 cancer cell lines. As MMP9 and MMP2 in the culture supernatants of L929 were previously reported, this was served as reference for MMP2 and MMP9 activity [9]. Culture supernatants of L929 and DLA cell lines were loaded into the adjacent wells of polyacrylamide gel. Approximate molecular weight of MMP2 (72 kDa) and MMP9 $(92 \mathrm{kDa})$ bands in the culture supernatant of DLA cells was calculated by correlating with previously reported results and it was in agreement with the previously reported results (Figure 1) [9]. Culture supernatants of DLA cell lines showed the presence of a high molecular weight gelatinase band which is completely absent in L929 cells.

3.2. Direct Inhibition of MMP by Tetracycline and GSH. Densitometric analysis of gelatin-zymographic gel was done to semiquantify the percentage of inhibition of MMP. Density of the clear zone developed in the gelatin-zymographic gel by MMP2 and MMP9 was calculated using Image J software. Decrease in density of the clear zones after treatment indicates the reduction in enzyme activity. Overnight incubation of tetracycline $(100 \mu \mathrm{g} / \mathrm{mL})$ and GSH $(100 \mu \mathrm{g} / \mathrm{mL})$ inhibited the gelatinase activity of MMP2 and MMP9 in the culture 


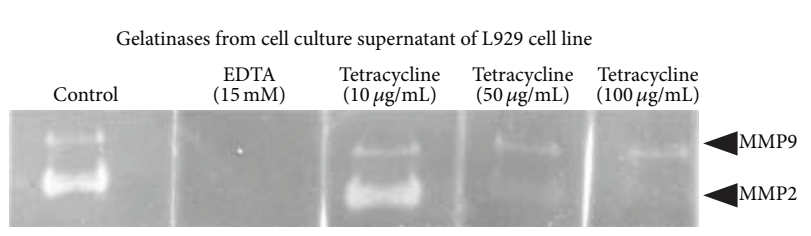

(a)

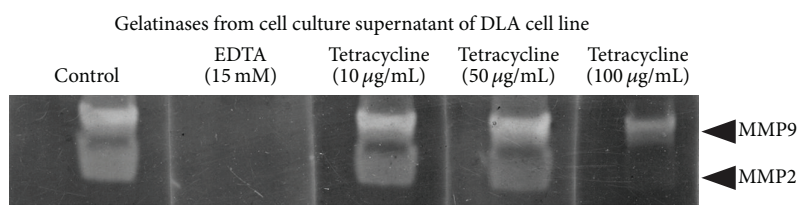

(c)

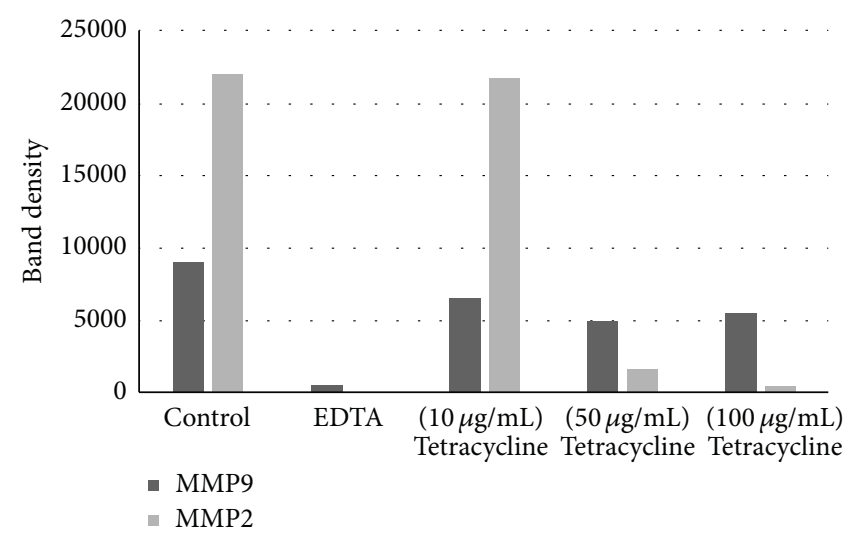

(b)

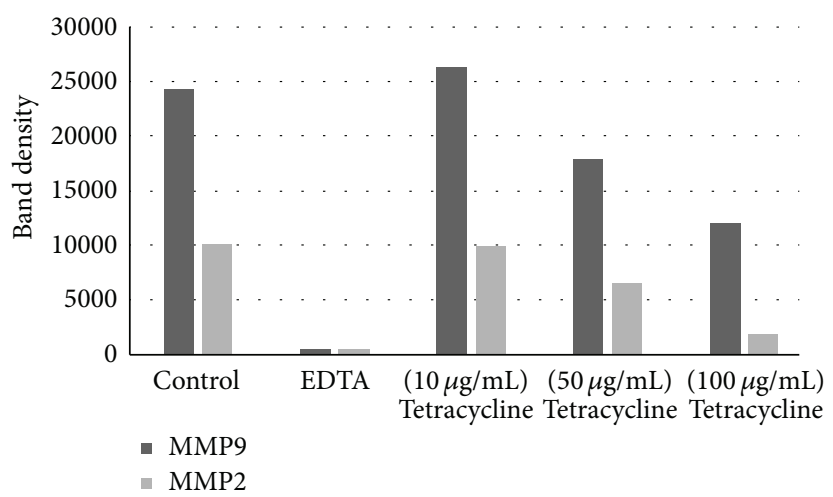

(d)

FIGURE 2: (a) Gelatin-zymography gel shows the concentration dependent inhibition of MMP2 (culture supernatant of L929) by tetracycline. EDTA is used as positive control to inhibit MMP activity. (b) In the graph, band density obtained in gelatin-zymographic gel after treatment with different concentrations of tetracycline was compared. Lower band density obtained during tetracycline treatment is a clear indication of MMP inhibition. (c) Gelatin-zymography gel shows the concentration dependent inhibition of MMP2 (culture supernatant of Dalton lymphoma cell lines) by tetracycline. (d) MMP2 proteolytic band showed lower band density compared to the control.

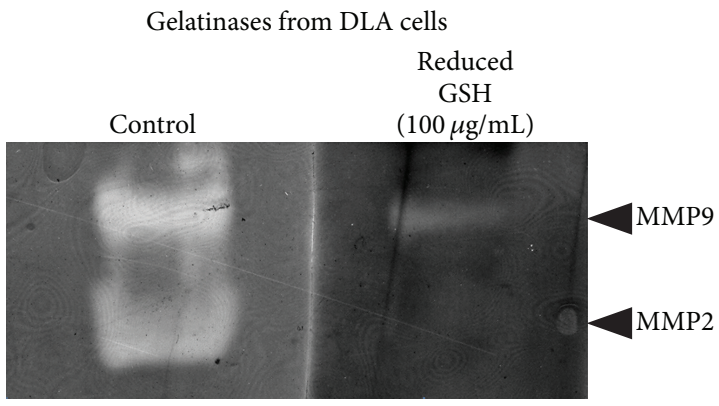

Figure 3: Reduced glutathione $(100 \mu \mathrm{g} / \mathrm{mL})$ inhibited MMP2 activity completely and MMP9 activity partly.

supernatants of L929 cells by $98.05 \%$ and $38.91 \%$, respectively (Figures 2(a) and 2(b)). $100 \mu \mathrm{g} / \mathrm{mL}$ of tetracycline was shown to inhibit MMP2 and MMP9 in the culture supernatant of DLA cell line by $80.97 \%$ and $50.58 \%$, respectively (Figures $2(\mathrm{c})$ and $2(\mathrm{~d})$ ). Incubation of gels with different tetracyclines ranging from 10 to $100 \mu \mathrm{g} / \mathrm{mL}$ showed that the inhibition exhibited by tetracycline on MMP2 and MMP9 activities was in a dose dependent manner. Treatment of $15 \mathrm{mM}$ EDTA

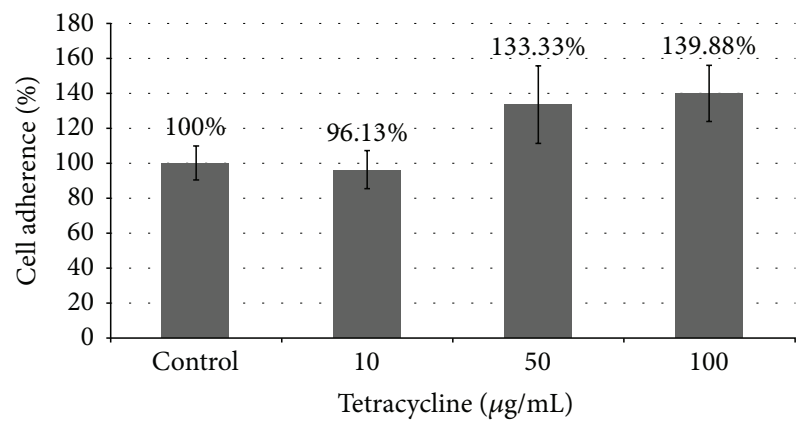

FIGURE 4: Tetracycline showed a concentration dependent increase in cell adherence.

served as a positive control as it is known to inhibit MMP by chelating metals such as $\mathrm{Ca}$ and $\mathrm{Zn} \mathrm{[10].} 100 \mu \mathrm{g} / \mathrm{mL}$ of GSH inhibited the gelatinase activity of MMP2 and MMP9 by $98.19 \%$ and $81.72 \%$, respectively (Figure 3 ).

3.3. Effect of Tetracycline on Cell Adherence. Increased adherence of cancer cell lines might prevent the initiation of 


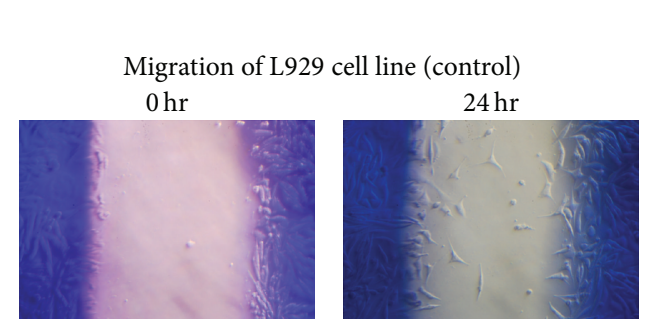

(a)

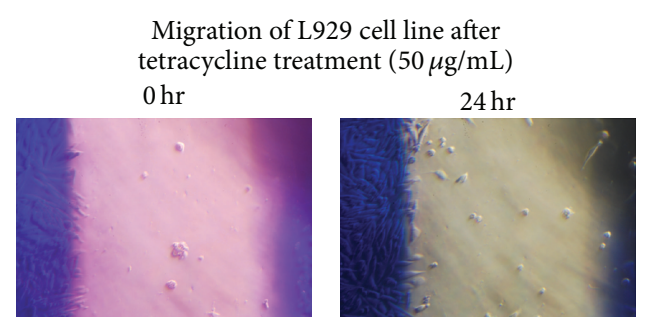

(b)

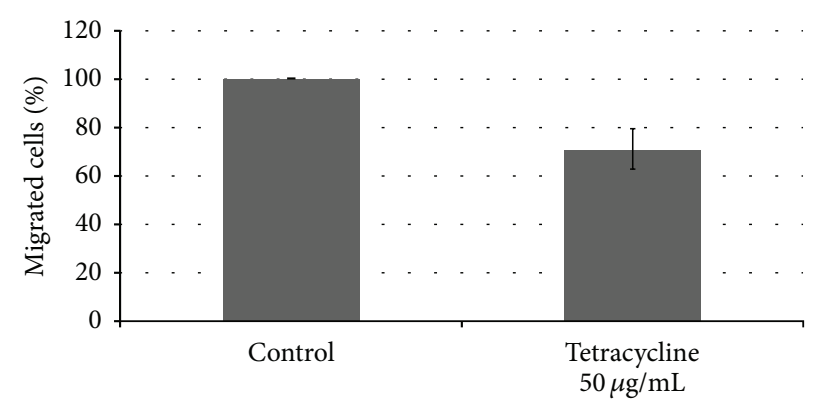

(c)

FIGURE 5: Effect of tetracycline on migration of L929 cells was studied by scratch assay. (a) Appearance of scratch at 0 and 24 hours without treatment is shown. (b) Appearance of scratch at 0 and 24 hours with tetracycline is shown. Tetracycline treated cells show less migration. (c) Graph shows the percentage of cell migration.

metastasis in the early stages of cancer. Therefore, to examine the effect of tetracycline on cell adherence, L929 cell suspension having cell density $10^{4}$ cells $/ \mathrm{mL}$ was added to the gelatin coated culture dishes and treated with two concentrations of tetracycline $(50$ and $100 \mu \mathrm{g} / \mathrm{mL})$. Treatment of 50 and $100 \mu \mathrm{g} / \mathrm{mL}$ of tetracycline for 4 hours increased the cell adherence by $33.33 \%$ and $39.88 \%$, respectively (Figure 4 ).

3.4. Effect of Tetracycline on Cell Migration-Scratch Assay. Effect of drugs on the migration of cancer cells indicates the anti-metastatic property of the drug, as metastasis involves the movement of cancer cells from one tumor site to other tissues. Drugs that affect the cell migration in vitro are supposed to prevent the metastasis. Effect of tetracycline on cancer cell migration was studied by scratch assay. Tetracycline $(50 \mu \mathrm{g} / \mathrm{mL})$ treatment for 24 hours inhibited the migration of L929 cancer cells by $29.16 \%$ compared to the control (Figure 5).

\section{Discussion}

Cancer cell metastasis is one of the major complications in cancer therapy as the cancer cell migrates out of its location by degrading the extracellular matrix and shifts to another location $[13,14]$. Cancer cell metastasis is mainly attributed to the protease activities of MMP2 and MMP9 [2]. In the present study tetracycline was shown to inhibit both matrix metalloproteinase activity and cell migration with concomitant increase in cell adherence. These results show that tetracycline (achromycin) has anti-metastatic property. Similar findings were also reported in different cancer cell lines with other tetracycline derivatives [15-17].
Rheumatoid arthritis is an autoimmune disease and the patients were detected to have higher expression of metalloproteinase in the synovial fluids [18]. Tetracycline derivatives were found to be successful in the treatment of rheumatoid arthritis [4]. As tetracycline was also reported to have anti-inflammatory properties, the clinical benefit observed for tetracycline against rheumatoid arthritis is not clearly defined [19]. Based on the results obtained from the present study it can be concluded that the success of tetracycline in clinical trials against rheumatoid arthritis is mainly due to metalloproteinase inhibition.

GSH is endogenously maintained inside the cells to check on the oxidative status. GSH acts as neutralizing agent against free radicals and protects cells from severe damage [20]. Previous reports showed that rheumatoid patients have lower GSH content in the serum [21, 22]. Interestingly, present in vitro studies showed that reduced glutathione directly inhibit the MMP activity. This clearly indicates that endogenous GSH has role in inhibiting the active MMPs in serum or synovial fluids. Based on our results, it is assumed that in addition to the endogenous inhibitor (tissue inhibitor of metalloproteinase (TIMP)), GSH might also have the role in keeping the MMP inactive [23]. Therefore, it is proposed that decreased GSH levels locally in plasma or synovial fluid might increase the MMP activity at those sites. Restoring the GSH levels in plasma or synovial fluids should alleviate the symptoms of rheumatoid arthritis.

\footnotetext{
Abbreviations

MMP: Matrix metalloproteinase

GSH: Reduced glutathione
} 
DLA: Dalton lymphoma cell line

RPMI: Roswell Park Memorial Institute medium

DMEM: Dulbecco's modified Eagle's media

PBS: Phosphate buffered saline

EDTA: Ethylenediaminetetraacetic acid.

\section{Acknowledgments}

The authors acknowledge Dr. M.D. Sohail Akhtar, and Dr. Manju, Central Drug research Institute, CSIR, Lucknow, for gifting L929 cell lines. They acknowledge the Department of Biotechnology, India, and the University of Calicut for research funds.

\section{References}

[1] J. Gross and C. M. Lapiere, "Collagenolytic activity in amphibian tissues: a tissue culture assay," Proceedings of the National Academy of Sciences of the United States of America, vol. 48, no. 6, pp. 1014-1022, 1962.

[2] M. R. Acharya, J. Venitz, W. D. Figg, and A. Sparreboom, "Chemically modified tetracyclines as inhibitors of matrix metalloproteinases," Drug Resistance Updates, vol. 7, no. 3, pp. 195-208, 2004.

[3] M. Björklund and E. Koivunen, "Gelatinase-mediated migration and invasion of cancer cells," Biochimica et Biophysica Acta, vol. 1755, no. 1, pp. 37-69, 2005.

[4] C. J. Smith, H. Sayles, T. R. Mikuls, and K. Michaud, "Minocycline and doxycycline therapy in community patients with rheumatoid arthritis: prescribing patterns, patient-level determinants of use, and patient-reported side effects," Arthritis Research \& Therapy, vol. 13, article R168, 2011.

[5] T. Itoh, H. Matsuda, M. Tanioka, K. Kuwabara, S. Itohara, and R. Suzuki, "The role of matrix metalloproteinase-2 and matrix metalloproteinase-9 in antibody-induced arthritis," Journal of Immunology, vol. 169, no. 5, pp. 2643-2647, 2002.

[6] B. R. Evans, R. A. Mosig, M. Lobl et al., "Mutation of membrane type-1 metalloproteinase, MT1-MMP, causes the multicentric osteolysis and arthritis disease winchester syndrome," The American Journal of Human Genetics, vol. 91, no. 3, pp. 572-576, 2012.

[7] E. Seidlitz, Z. Saikali, and G. Singh, "Use of tetracyclines for bone metastases," in Bone Metastasis, G. Singh and S. Rabbani, Eds., pp. 293-303, Humana Press, New York, NY, USA, 2005.

[8] L. M. Prescott, Microbiology, McGraw-Hill, New York, NY, USA, 5th edition, 2002.

[9] Z. Qiu, C. Dillen, J. Hu et al., "Interleukin-17 regulates chemokine and gelatinase B expression in fibroblasts to recruit both neutrophils and monocytes," Immunobiology, vol. 214, no. 9-10, pp. 835-842, 2009.

[10] R. Gendron, D. Grenier, T. Sorsa, and D. Mayrand, "Inhibition of the activities of matrix metalloproteinases 2, 8, and 9 by chlorhexidine," Clinical and Diagnostic Laboratory Immunology, vol. 6, no. 3, pp. 437-439, 1999.

[11] A. Vijayalakshmi and V. Girish, "Affordable image analysis using NIH image/imageJ," Indian Journal of Cancer, vol. 41, no. 1, p. $47,2004$.

[12] C. C. Liang, A. Y. Park, and J. L. Guan, "In vitro scratch assay: a convenient and inexpensive method for analysis of cell migration in vitro," Nature Protocols, vol. 2, no. 2, pp. 329-333, 2007.

[13] M. Li, N. Amizuka, K. Takeuchi et al., "Histochemical evidence of osteoclastic degradation of extracellular matrix in osteolytic metastasis originating from human lung small carcinoma (SBC5) cells," Microscopy Research and Technique, vol. 69, no. 2, pp. 73-83, 2006.

[14] H. Kobayashi, "Mechanism of tumor cell-induced extracellular matrix degradation inhibition of cell-surface proteolytic activity might have a therapeutic effect on tumor cell invasion and metastasis," Nihon Sanka Fujinka Gakkai Zasshi, vol. 48, no. 8, pp. 623-632, 1996.

[15] R. S. Fife and G. W. Sledge Jr., "Effects of doxycycline on in vitro growth, migration, and gelatinase activity of breast carcinoma cells," Journal of Laboratory and Clinical Medicine, vol. 125, no. 3, pp. 407-411, 1995.

[16] R. S. Fife, G. W. Sledge Jr., B. J. Roth, and C. Proctor, "Effects of doxycycline on human prostate cancer cells in vitro," Cancer Letters, vol. 127, no. 1-2, pp. 37-41, 1998.

[17] B. L. Lokeshwar, M. G. Selzer, B. Q. Zhu, N. L. Block, and L. M. Golub, "Inhibition of cell proliferation, invasion, tumor growth and metastasis by an oral non-antimicrobial tetracycline analog (COL-3) in a metastatic prostate cancer model," International Journal of Cancer, vol. 98, no. 2, pp. 297-309, 2002.

[18] D. Ahrens, A. E. Koch, R. M. Pope, M. Stein-Picarella, and M. J. Niedbala, "Expression of matrix metalloproteinase 9 (96kd gelatinase B) in human rheumatoid arthritis," Arthritis and Rheumatism, vol. 39, no. 9, pp. 1576-1587, 1996.

[19] A. Jain, L. Sangal, E. Basal, G. P. Kaushal, and S. K. Agarwal, "Anti-inflammatory effects of erythromycin and tetracycline on Propionibacterium acnes induced production of chemotactic factors and reactive oxygen species by human neutrophils," Dermatology Online Journal, vol. 8, no. 2, p. 2, 2002.

[20] D. Gerard-Monnier and J. Chaudiere, "Metabolism and antioxidant function of glutathione," Pathologie Biologie, vol. 44, no. 1, pp. 77-85, 1996.

[21] M. Q. Hassan, R. A. Hadi, Z. S. Al-Rawi, V. A. Padron, and S. J. Stohs, "The glutathione defense system in the pathogenesis of rheumatoid arthritis," Journal of Applied Toxicology, vol. 21, no. 1, pp. 69-73, 2001.

[22] A. Kamanlı, M. Nazıroğlu, N. Aydılek, and C. Hacıevlıyagil, "Plasma lipid peroxidation and antioxidant levels in patients with rheumatoid arthritis," Cell Biochemistry and Function, vol. 22, no. 1, pp. 53-57, 2004.

[23] D. E. Gomez, D. F. Alonso, H. Yoshiji, and U. P. Thorgeirsson, "Tissue inhibitors of metalloproteinases: structure, regulation and biological functions," European Journal of Cell Biology, vol. 74, no. 2, pp. 111-122, 1997. 


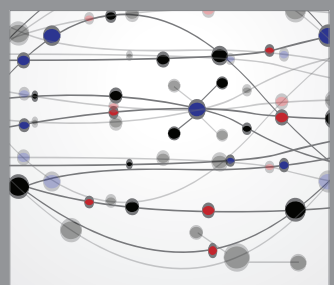

The Scientific World Journal
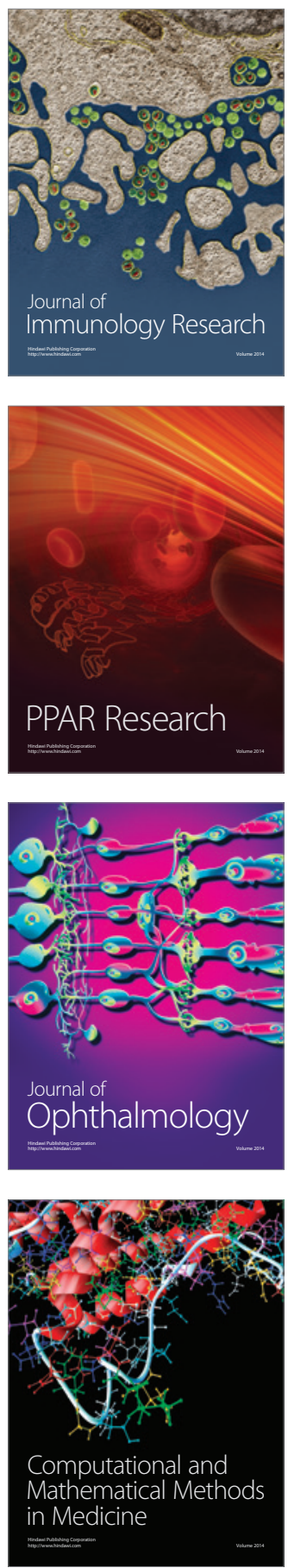

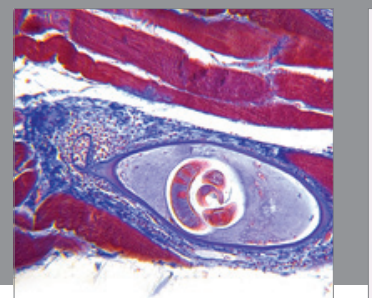

Gastroenterology

Research and Practice
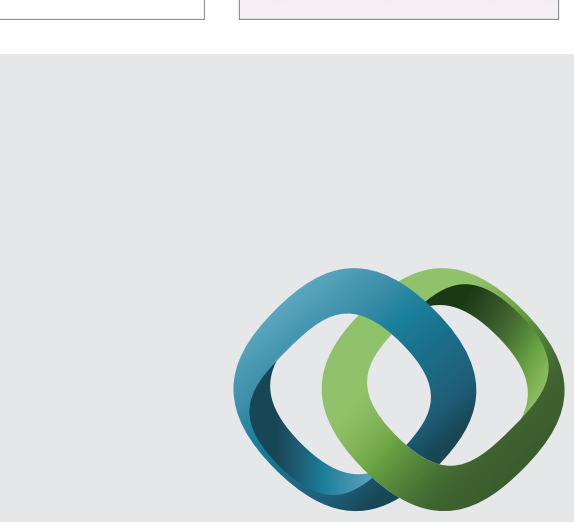

\section{Hindawi}

Submit your manuscripts at

http://www.hindawi.com
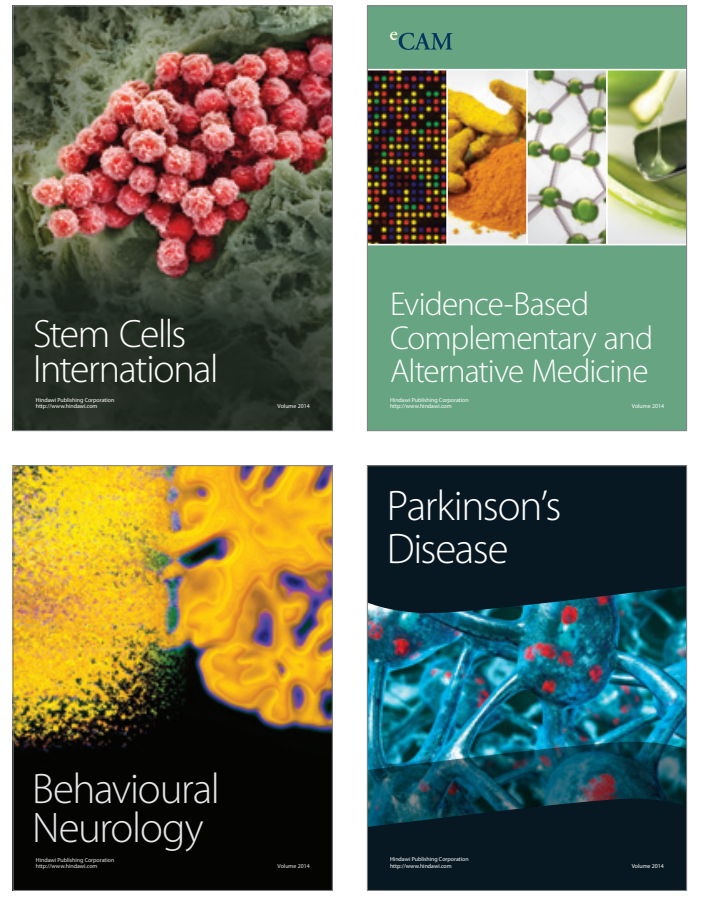
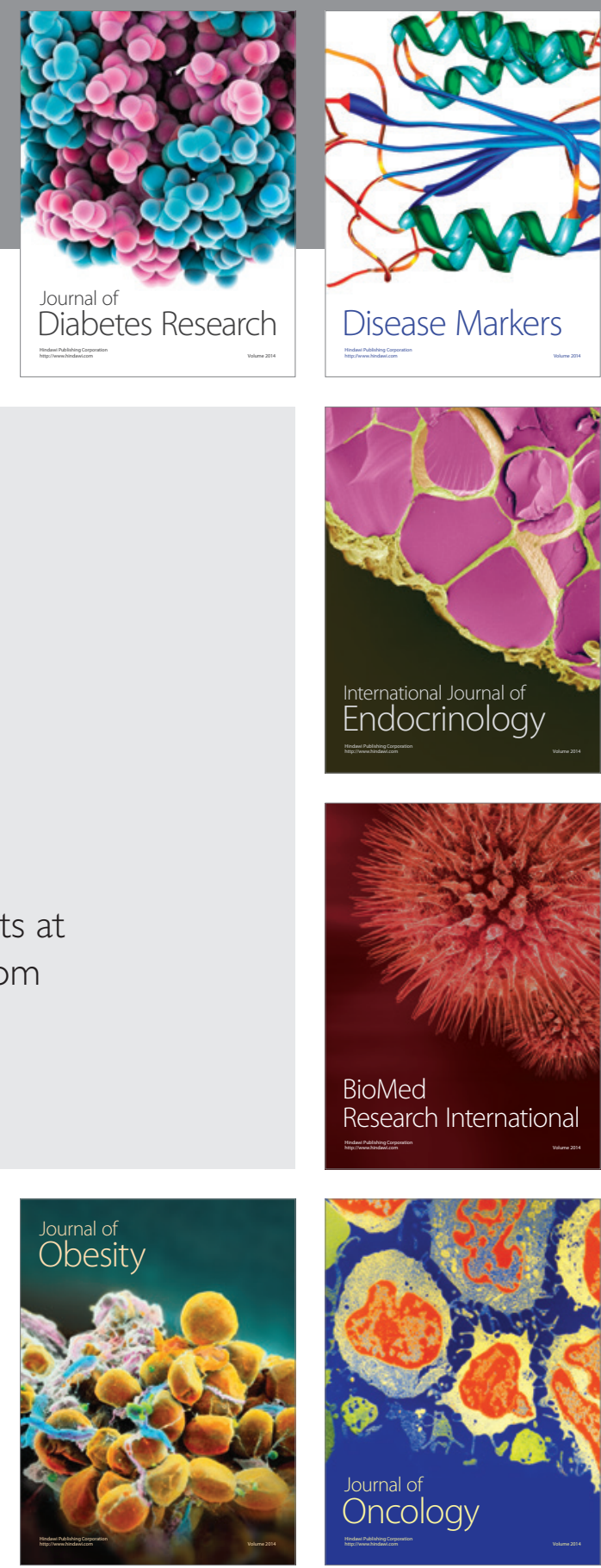

Disease Markers
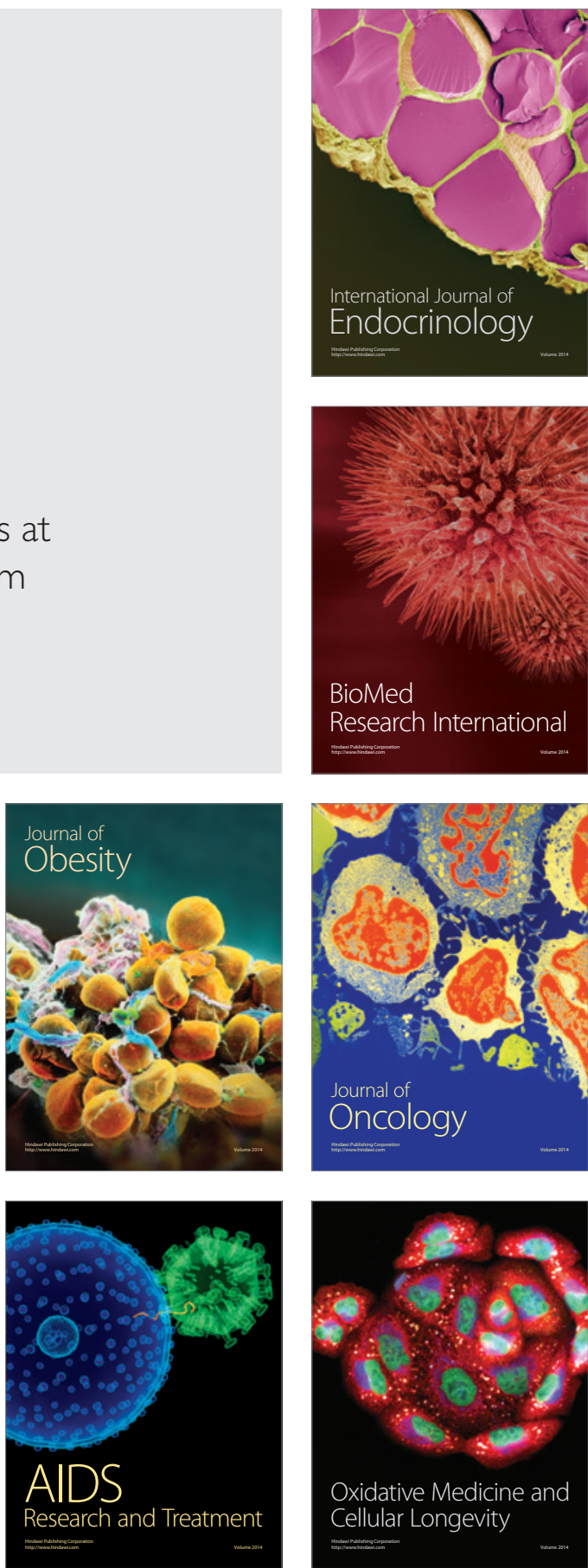